\title{
A região do Contestado, a fome e a pobreza como permanência da guerra
}

\author{
Vanessa Maria Ludka ${ }^{1}$
}

\begin{abstract}
RESUMO: A noção que se tem corretamente do que seja fome é uma noção bem incompleta, como já dizia Josué de Castro. 0 tema da fome é bastante vasto e complexo. Seus aspectos são vários, embora os fundamentos e origens do fenômeno conduzam a uma conclusão lógica, a de que a fome é um problema social. Dentro deste escopo, o objetivo desta pesquisa foi compreender a fome e a pobreza existentes na Região do Contestado, buscando avaliar se a mesma é uma herança da Guerra do Contestado ou uma questão social, política, econômica e cultural que permanece ao longo do tempo. Para formar e designar como Região do Contestado a área de estudo, optou-se por estudar duas associações de municípios que compõem as microrregiões catarinenses: a AMPLANORTE e AMARP - a estas duas, se dá, o nome de Região do Contestado, por serem mais do que representativas no contexto das análises desta pesquisa. Percebe-se que a persistência da fome e da pobreza, não está liga à escassez ou à dificuldade física de acesso ao alimento, mas, sim, ao baixo poder aquisitivo de boa parcela da população que por conta disso, não possui renda suficiente para que possam alimentar-se de forma adequada.
\end{abstract}

Palavras-chave: Fome; Pobreza; Região do Contestado; Guerra do Contestado; Santa Catarina.

\section{Contestado region, famine and poverty as continuities the war}

\begin{abstract}
The correct idea currently in use about famine is a very incomplete one, as pointed out by Josué de Castro. Famine as a topic is a wide array of possible discussions, and a complex one. Its aspects vary, although the fundaments and the origins of this phenomenon can lead to the logical conclusion that famine is a social problem. Within this threshold, the main objective of this research was to understand famine and poverty that exist in the Contestado Region, aiming to evaluate if it was inherited from the Contestado War or a social, political, economic and cultural issue that lingers through time. To define and form the Contestado Region as the area of study, we chose to study two municipal associations in Santa Catarina state: AMPLANORTE and AMARP these two associations are labeled as the Contestado Region, since they more than representative in the context in which this research's analyses were made. We can note that the resilience of famine and poverty in this region is not connected to scarcity or physical difficulties in accessing food. It is better connected to the low household income of many of the inhabitants of the regione that, due to this reality, cannot save enough income to feed in an adequate manner.
\end{abstract}

Keywords: Famine; Poverty; Contestado Region; Contestado War; Santa Catarina.

- Enviado em 25/09/2016

- Aprovado em 18/11/2016

${ }^{1}$ Professora da Universidade Estadual do Norte do Paraná. Doutora em Geografia. E-mail: vanessaludka@gmail.com 


\section{INTRODUÇÃO}

Discutir o problema da fome, já não é um assunto tão recente, pois desde meados do século XX esse tema foi discutido por Josué de Castro, um dos maiores estudiosos sobre o tema, que se tornou referência nesta discussão. A fome é um fenômeno essencialmente geográfico, pois como bem coloca Josué de Castro (2001), a fome é universal e nenhum continente escapa a sua ação nefasta.

O Objetivo desta pesquisa é compreender a fome e a pobreza existentes na Região do Contestado, buscando avaliar se a mesma é uma herança da Guerra do Contestado ou apenas fruto de questões sociais, políticas, econômicas e, mesmo, culturais regionais.

Este estudo, por meio de estudos geográficos decorrentes da produção e transformação do espaço urbano regional, é resultante de uma pesquisa teórica e empírica da fome e da pobreza, além das abordagens socioespaciais da Região do Contestado Catarinense.

Esta pesquisa descreve os elementos que acarretaram no desenrolar da Guerra do Contestado em território compreendido entre os Estados do Paraná e de Santa Catarina. Apresenta as relações sociopolíticas que desencadearam na guerra e nas suas manifestações sobre o espaço geográfico regional. Dimensionando as consequências às comunidades que viviam na região em questão, como centro do poder de tomada de decisões e as influências deste poder, com a implantação da Ferrovia São Paulo - Rio Grande, a implantação da Cia. Lumber e do processo de colonização das terras em questão.

O Mapa 1 representa a localização da área territorial político-jurídica em questão, ou seja, a região em estudo. Para formar e designar como Região do Contestado, optou-se por estudar duas associações de municípios que compõem as seguintes microrregiões catarinenses: a AMPLANORTE e AMARP - a estas duas se dá, nesta tese, o nome de Região do Contestado, por serem mais do que representativas no contexto das análises desta pesquisa. A AMPLANORTE é a Associação dos Municípios do Planalto Norte Catarinense; a mesma é composta pelos seguintes municípios: Bela Vista do Toldo, Canoinhas, Irineópolis, Itaiópolis, Mafra, Major Vieira, Monte Castelo, Papanduva, Porto União e Três Barras. Já a AMARP é Associação dos Municípios do Alto Vale do Rio do Peixe, que é composta pelos consecutivos municípios: Arroio Trinta, Caçador, Calmon, Fraiburgo, Iomerê, Lebon Régis, Macieira, Matos Costa, Pinheiro Preto, Rio das Antas, Salto Veloso, Timbó Grande e Videira. 


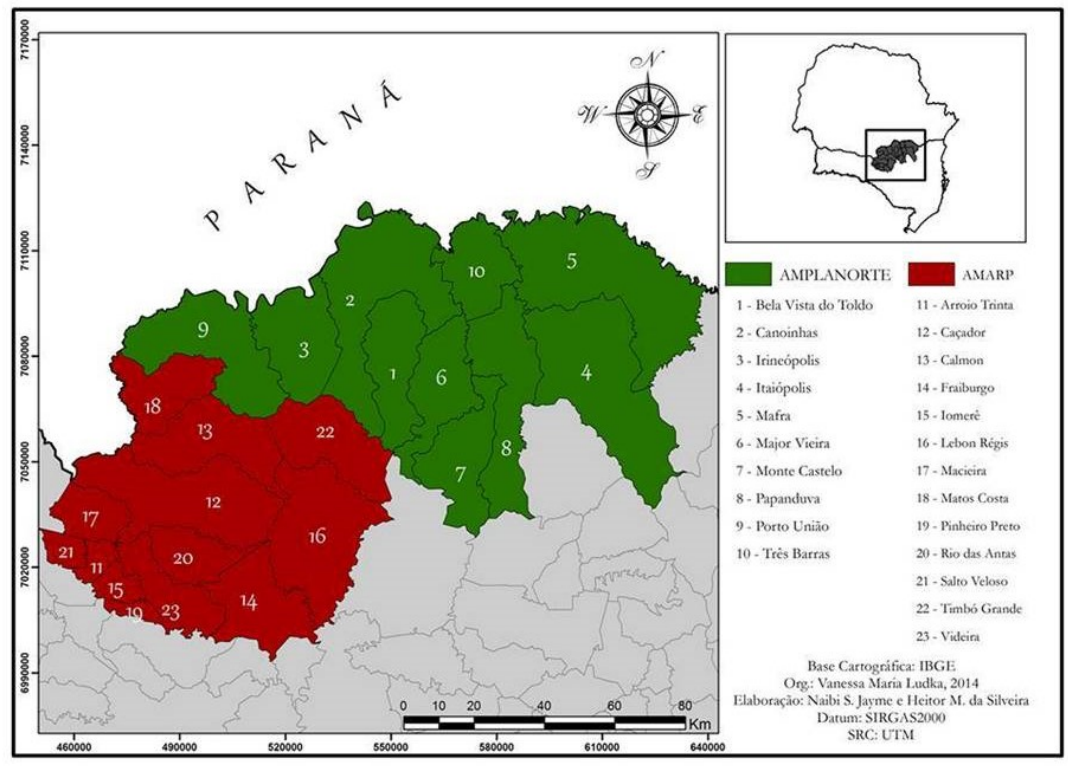

Fonte: Ludka (2014) Adaptado de Base Cartográfica do IBGE (2014).

A delimitação da área de estudo se deu na escolha dessas duas associações pelo motivo de que lá ocorreram as principais batalhas da Guerra do Contestado para abrir e entregar aquele espaço geográfico para o capital estrangeiro e a imigração/colonização estrangeira, que se encontrava em posse dos caboclos fazia aproximadamente dois séculos. Há que se mencionar que tal região possui cinco municípios polos regionais, a saber: Mafra, Canoinhas, Porto União, Caçador e Videira, estas cercadas por municípios com baixos índices socioeconômicos, IDH baixo e alto índice de pobreza. Para tanto, nesta pesquisa, se utiliza o termo Região do Contestado para delimitar a(s) região(s) de estudo desta tese, ou seja, dos municípios que compõem a AMPLANORTE e a AMARP que se caracterizam como Região do Contestado, tendo em vista o papel de importância regional dessa região geográfica no decorrer da guerra ocorrida entre 1912 e 1916.

\section{CONTESTADO EM GUERRA: ESTOPINS DE UM MASSACRE}

Ao longo dos anos, a Guerra do Contestado vem sendo analisada sob os olhares de uma multiplicidade de perspectivas: do historiador, do geógrafo, do político, do sociólogo, do 
folclorista, dos artistas, cada qual com sua abordagem, referencial conceitual, métodos e contribuições. Analisar geograficamente a Guerra do Contestado só é possível por meio da compreensão da mesma enquanto "fenômeno histórico vivo e multifacetado e não como fórmula abstrata morta" (MACHADO, 2004, p.36). Significa pensar o conflito a partir de suas motivações, da forma com que se processou e, mais arriscadamente, perceber que as consequências ainda hoje são sentidas - sobretudo nestes anos que se rememoram as referências ao Centenário do Conflito, cuja Guerra se estendeu entre os anos de 1912 e 1916.

Ao contrário da Guerra de Canudos, a Guerra do Contestado teve numerosos e diversos líderes que ainda são cultuados pela memória do povo da região. Além destes líderes, fatos, fenômenos e acontecimentos contribuíram para tornar o conflito (e suas consequências) uma possibilidade ímpar de ser analisada e pesquisada.

De 1912 a 1916, ocorreram, em Santa Catarina, numa área em litígio com o vizinho Paraná, os fatos mais sangrentos das suas histórias, quando a população do Planalto pegou em armas e deu o grito de guerra, no episódio que ficou conhecido como a Guerra do Contestado. Foram várias as causas do conflito armado, pois, na mesma época e no mesmo lugar, ocorreu um movimento messiânico de grandes proporções, uma disputa pela posse de terras, uma competição econômica pela exploração de riquezas naturais, e uma questão de limites interestaduais (FRAGA, 2010, p. 139).

A Guerra do Contestado, em si, foi definidora dos territórios atuais de Santa Catarina e do Paraná, além de constituir aquelas denominadas Região do Contestado Catarinense e Sul Paranaense, onde, conforme Eduardo Galeano (1986), verificou-se uma das maiores guerras civis do continente americano, pois o genocídio de milhares de camponeses pobres foi a sua principal marca. A Guerra do Contestado é um episódio complexo, pois é alimentado por vários fatores que se entrelaçam, sejam de ordem social, política, econômica, cultural, sejam de ordem religiosa (FRAGA, 2009, p. 17).

A Guerra do Contestado reuniu, no mesmo tempo e no mesmo espaço geográfico, mais de 30 mil pessoas - habitantes da região na época -, desde fazendeiros, em defesa de suas propriedades, até posseiros tentando se manter em terras devolutas, "fanatizados" por promessas messiânicas, e oportunistas que viam no movimento ocasião para exercerem pressões políticas acerca dos limites disputados entre Santa Catarina e o Paraná. A guerra, durante quatro anos, ceifou a vida de milhares de sertanejos. 
Nos últimos duzentos anos, centenas de movimentos messiânicos aconteceram. Alguns foram pequenos, outros obtiveram destaque por envolver pessoas marginalizadas, insatisfeitas e ignorantes que, com expressões, concentraram-se em figuras carismáticas, como os monges conhecidos por João Maria e José Maria. Para que um movimento se caracterize como messiânico, deve contar com as propostas básicas da crença popular da volta do Messias. O Contestado foi também um movimento tido como messiânico. Os responsáveis pela caracterização deste movimento foram os monges que deixaram, por onde passaram, registros em todo Sul do País. Eram profetas, curandeiros, santos, conselheiros, que irradiavam amor, devoção, simplicidade e caridade (FRAGA, 2006).

Pregador ou charlatão, curandeiro ou apóstolo, santo ou guerreiro, como diria Nilson Thomé (1992), a figura do Monge permanece até hoje no imaginário coletivo da população envolvida na causa do Contestado. Esse 'santo' não foi um homem, foram vários que confundiram e entrelaçaram suas vidas para se tornarem apenas um santo. Em alguns lugares, como Porto União (SC) e União da Vitória (PR), a crença no monge ainda faz parte do cotidiano, seja nos batismos nas fontes de água, seja na visitação à Gruta do Monge ou ao Morro da Cruz, ou mesmo nas histórias contadas.

As forças militares, que estiveram no Contestado para impor a ordem e a lei, e afugentar bandos de fanáticos, em tarefa que parecia fácil, defrontaram-se com um verdadeiro exército rival, disciplinado, formado por gente hábil, destemida, idealista, conhecedora do terreno e dos segredos da natureza, que transformaram em pesadelos as investidas oficiais, ao aplicar táticas de guerrilha, envolvendo os soldados em mortíferas ciladas. Só depois de quase dez mil sepulturas é que as tropas legais se convenceram de que tinham estado diante de um inimigo não inferior, e que a vitória final aconteceu porque a astúcia dos camponeses não resistiu ao poderio bélico e à inteligência e persistência militar (MONTEIRO, 1974).

No dia 20 de outubro de 1916, foi assinado o Acordo de Limites pelo presidente do Paraná, Afonso Alves Camargo, e pelo governador de Santa Catarina, Felipe Schmidt. O Paraná ficou com 20.310 quilômetros quadrados e Santa Catarina com 27.570 quilômetros quadrados. Os paranaenses “cederam" Itaiópolis, Papanduva e Canoinhas, mas recuperaram Palmas e Clevelândia. E a cidade da margem esquerda do Iguaçu, que havia sido fundada por paulistas, acabou sendo dividida: União da Vitória ficou para o Paraná, e Porto União, para Santa Catarina (THOMÉ, 2003). No que concerne à repercussão da Guerra do Contestado sobre o espaço agrário regional, faz-se importante lembrar que o ano de 1917 é tido 
historicamente como o ano da "limpeza" das terras que estavam sob domínio da Lumber e dos coronéis (FRAGA, 2010).

Os relatos históricos produzidos nas últimas décadas não consideraram a limpeza étnica no ano mencionado; os mesmos coincidem com a criação de vários municípios, na forma da lei vigente, para garantir a posse do território, seja na parte que coube à Santa Catarina, seja na que coube ao Paraná. Dentre eles se podem destacar Mafra, União da Vitória, Cruzeiro (hoje Joaçaba) e Chapecó, além dos já existentes, como Canoinhas, Curitibanos e Campos Novos. Tais cidades passaram a ser administradas pelos coronéis de então, todos com possibilidades de contratar farta mão-de-obra para expulsar e matar os posseiros restantes no ano da limpeza, 1917 (FRAGA, 2010). Assim sendo, o território outrora contestado passou a ser rapidamente ocupado por milhares de migrantes europeus e excedentes das colônias do Rio Grande do Sul e outras regiões de Santa Catarina, ocupando as terras de posse dos caboclos, sob domínio e direito de colonização da Cia. Lumber.

\section{AS FOMES DE COMIDA E AS INVISÍVEIS}

Dentre todos os direitos humanos, o direito à alimentação é, seguramente, o mais constante e maciçamente violado em nosso planeta. A fome assemelha-se ao crime organizado. (Jean Ziegler em Destruição em massa: Geopolítica da Fome, 2013 p. 31).

A exclusão social, a miséria e a fome são fenômenos sociais mundiais tão antigos quanto o ideal pela busca de uma sociedade equitativa. Impressiona profundamente a sua face mais cruel: a fome, como impossibilidade dos cidadãos de acessar a direitos sociais básicos, em virtude do processo de concentração de renda e acesso desigual às oportunidades na sociedade brasileira. Tratar o problema da fome como questão nacional e não como fatalidade individual é responsabilidade de toda sociedade e dos governos, nas suas esferas federal, estaduais e municipais.

Nesse princípio do século XXI, com aproximadamente sete bilhões de seres humanos com que conta o planeta, por volta da metade vive na pobreza, com um poder aquisitivo equivalente a menos de dois dólares estadunidenses por dia. Perto de dois bilhões sofrem de graves carências de ferro, iodo, vitamina A, de outras vitaminas e minerais. Mais de um bilhão de pessoas não têm acesso à água potável e por volta de 795 milhões são vítimas de subnutrição (pouco mais de um em cada nove), o que significa que elas nem sempre dispõem 
de ração alimentar para cobrir suas necessidades energéticas básicas, em outras palavras, que elas têm fome quase todos os dias (FAO, 2015).

Castro questiona (1961, p.46) que será a calamidade da fome um fenômeno natural, inerente à própria vida, uma contingência irremovível como a morte? Ou será a fome uma praga social?

[...] a fome coletiva é um fenômeno de categoria social, provocado via de regra, pelo aproveitamento inadequado das possibilidades e recursos naturais ou pela má distribuição dos bens de consumo obtidos. [...] não é possível admitir-se ser a fome um fenômeno natural, uma vez que ela é condicionada muito mais por fatores de natureza econômica do que pelos de natureza geográfica. (CASTRO, 1961, p. 371).

[...] a fome não é um fenômeno natural, e sim, um produto artificial de conjunturas econômicas defeituosas: um produto de criação humana e, portanto capaz de ser eliminado pela vontade criadora do homem. (CASTRO, 1966, p. 23).

A fome constitui uma das expressões da problemática social, em decorrência do processo histórico de concentração de renda. A fome não é decorrência da baixa produção de alimentos, mas da falta de recursos da população, que não possui renda suficiente para adquiri-los.

0 primeiro dos nossos objetivos é demonstrar que a fome, apesar de constituir fenômeno universal, não traduz uma imposição da natureza. Estudando a fome em diferentes regiões da Terra, poremos em evidência o fato de que, via de regra, não são as condições naturais que conduzem os grupos humanos à situação de fome, e sim certos fatores culturais, produto de erros e defeitos graves das organizações sociais em jogo. A fome determinada pela inclemência da natureza constitui um acidente excepcional, enquanto que a fome como praga feita pelo homem constitui uma condição habitual nas mais diferentes regiões da Terra: toda terra ocupada pelo homem tem sido por ele transformada em terra da fome (CASTRO, 1961 p. 79).

De acordo com Ziegler (2013), para melhor circunscrever a Geografia da Fome, a distribuição da mesma sobre o planeta, é necessário recorrer primeiro à distinção que, segundo a ONU e suas agências especializadas, são a fome estrutural e fome conjuntural.

Em suma, podemos dizer que a "fome conjuntural" é provocada pela derrota brutal, imprevista, e em curto prazo de toda a infraestrutura econômica e social de uma sociedade. Como, por exemplo, a devastação e desnutrição de campos, estradas e 
poços por causa de uma seca ou de um furacão; ou como consequência de uma guerra, onde são incendiadas as casas, as pessoas são laçadas à rua, se acaba com os mercados, as pontes quebradas. Subitamente deixa de haver alimentos e milhões de pessoas se veem na indigência da noite para o dia. Por outro lado, a "fome estrutural" corresponde a falta permanente de alimentos à ausência persistente de uma alimentação adequada. Ela se deve ao subdesenvolvimento geral da economia de um país, à insuficiência de suas forças de produção e de suas infraestruturas e à extrema pobreza da maioria dos seus habitantes. As pessoas morrem lentamente por causa do grande número de doenças que as assolam, da falta de vitaminas ou do kwashiorkor ${ }^{2}$. Resumindo, a "fome estrutural" não provém de uma catástrofe externa, mas é inerente às estruturas da sociedade (ZIEGLER, 2002, p. 32).

Ziegler (2013) destaca o problema da má nutrição, ou seja, seres destruídos pela subalimentação, e a FAO não os ignora, mas os recenseia à parte. A subalimentação provém da falta de calorias e a má nutrição, da carência em matéria prima dos micronutrientes vitaminas e sais minerais. Vários milhões de crianças de menos de 10 anos morrem anualmente de má nutrição aguda e severa. Para designar a má nutrição, as Nações Unidas utilizam habitualmente a expressão "silente hunger" - "fome silenciosa". Ziegler (2013) prefere chamar de "fome invisível", imperceptível ao olhar, às vezes também ao olhar do médico.

De acordo com a FAO (2015), a "fome oculta" ou "fome silenciosa", de acordo com a ONU ou "Fome invisível", para Ziegler, é a falta de, ou de inadequação da ingestão de micronutrientes, resultado em diferentes tipos de desnutrição, como anemia por deficiência de ferro e de vitamina A.

Já Mazoyer e Roudart (2010), ao abordar a fome, destacam que quanto aos surtos de fome que eclodem aqui e ali quando há uma seca, inundação, tempestade, doença das plantas, dos animais ou dos homens, ou ainda da guerra, elas não deixam de ser, por outro lado, a consequência última da pobreza e da subnutrição. Na verdade, esses acidentes climáticos, biológicos ou políticos levam a fome apenas às regiões do mundo com amplas camadas da

\footnotetext{
${ }^{2}$ Kwashiorkor refere-se a uma patologia resultante da ingestão insuficiente de proteínas, que se caracteriza pela presença de edema, irritabilidade, anorexia, dermatoses ulceradas e hepatomegalia, causada pelo acúmulo de gordura no fígado. Esta desordem foi nomeada pelo pediatra jamaicano Cicely Williams, apresentando-o à comunidade médica em um artigo de sua autoria publicado no ano de 1935. Tipicamente, esta condição é observada em indivíduos que vivem em regiões muito pobres, onde há escassez de alimentos. Também pode ocorrer em casos de infecções parasitárias, doenças ou condições que interferem na absorção proteica. Além disso, dietas veganas são conhecidas por levarem a esta condição. Insuficiência hepática, resultante de uma infecção por aflatoxina, é uma causa bem conhecida de kwashiorkor.
} 
população que sofrem já de uma pobreza e de uma insegurança alimentar tão grandes que não dispõem dos meios para lutar de maneira eficaz contra essa catástrofe e suas consequências.

Percebe-se que a persistência desse fenômeno não está ligada à escassez ou dificuldade física de acesso aos alimentos, mas, ao baixo poder aquisitivo de boa parcela da população que, por conta disso, não proporciona renda suficiente para que essas pessoas possam alimentar-se de forma adequada diariamente.

\begin{abstract}
Eu acredito que já é passado o tempo em que as pessoas pobres podiam se conformar segundo a frase das Escrituras: "Aos pobres é reservado é reservado o reino dos céus". Agora devemos pensar que aos pobres deve também ser reservado o reino da Terra, pois a Terra é para todos os homens e não só para um grupo de privilegiados (CASTRO, 2001, p. 125). Geografia da Fome
\end{abstract}

No que diz respeito à fome na Região do Contestado, não difere muito da realidade brasileira abordada por Josué de Castro (2001 p. 280), pois a fome, no Brasil, é consequência, antes de tudo, do seu passado histórico, com seus grupos humanos, sempre em luta e quase nunca em harmonia com os quadros naturais, aventura desdobrada em ciclos sucessivos de economia destrutiva ou pelo menos, desequilibrante da saúde econômica da nação. No que consiste à Região do Contestado, neste contexto, pode-se citar a exploração da madeira nativa desde antes da Guerra do Contestado, com a concessão à empresa Lumber de explorar $15 \mathrm{~km}$ de cada lado da ferrovia São Paulo Rio Grande. Atualmente, a região é grande parte ocupada pela plantação do pinus, álamo, monocultivo do tabaco, e granjas de frango.

O Relatório de Insegurança Alimentar no Mundo de 2014, publicado pela FAO, revela que o Brasil reduziu de forma muito expressiva a fome, a desnutrição e subalimentação nos últimos anos. 0 Indicador de Prevalência de Subalimentação, medida empregada pela FAO há cinquenta anos para dimensionar e acompanhar a fome em nível internacional, atingiu nível abaixo de 5\%, o limite estatístico da medida, abaixo do qual se considera que um país superou o problema da fome, tudo isso graças a programas governamentais de transferência de renda à população mais carente, um deles o Programa Fome Zero.

O Fome Zero é um programa do Governo Federal implantado no primeiro mandado do governo do Presidente Luiz Inácio Lula da Silva, e o projeto visa ao direito de alimentação da população brasileira. Uma maneira de garantir cidadania às populações vulneráveis à fome. 
No Brasil, existem mais de 10 milhões de pessoas abaixo da linha da pobreza, o que significa que nem o acesso à alimentação é saudável.

\footnotetext{
"Num país que conta com tantas terras férteis e com tanta gente que quer trabalhar, não deveria haver razão alguma para se falar em fome. No entanto, milhões de brasileiros [...] sobrevivem milagrosamente abaixo da linha da pobreza, quando não morrem de miséria, mendigando um pedaço de pão. Por isso, defini entre as prioridades de meu governo um programa de segurança alimentar que leva o nome de Fome Zero." (Discurso de posse do Presidente Lula - 1/1/2003) (BRASIL, 2003).
}

O presidente Luiz Inácio Lula da Silva, ao apresentar o combate à fome e à pobreza como prioridade para seu primeiro mandato, em 2003, lança uma estratégia nacional que cria, implementa e investe recursos financeiros e humanos em diversos programas e ações que se integram numa meta comum, que une a todos, que é zerar a fome e a extrema pobreza no país. Ao afirmar que a missão de sua vida estaria cumprida se, ao final de seu governo, cada brasileiro tivesse acesso a três refeições diárias, o presidente colocou os temas da fome, da segurança alimentar e nutricional e do combate à pobreza na agenda política nacional e expôs à sociedade a linha mestra de um amplo projeto de Nação.

Voltando os olhares para a Região do Contestado, houve também grandes mudanças socioeconômicas com a implantação do Projeto Fome Zero, porém a região ainda é marcada pela fome e pela pobreza, sofreu com a fome conjuntural, hoje a fome estrutural, crônica, oculta ou invisível é a realidade da região em estudo.

Em estudos realizados na região, foi possível constatar que a fome conjuntural foi marcante no período da Guerra do Contestado, a fome estrutural está presente atualmente, pois a falta de recursos para a aquisição de alimentos e a ausência persistente de uma alimentação adequada é a realidade de muitas famílias daquela região. A fome crônica também é a realidade de muitas famílias, pois muitas delas comem menos do que deveriam para desenvolver seu organismo e levar uma vida saudável. E a fome oculta ou invisível é a mais presente, pois muitas famílias não ingerem as vitaminas necessárias para manter uma vida saudável. 


\section{LUGARES ESQUECIDOS: POBREZA, A HUMANIDADE AMEAÇADA DO/NO CONTESTADO}

Agora, apresenta-se a discussão do conceito de pobreza e dados que a retratam na Região do Contestado, pois um indivíduo, ou toda uma sociedade, poderá estar livre da fome e ainda assim ser pobre, bastando que sua pobreza se expresse através do não-acesso à educação e a cuidados de saúde, de condições insalubres de moradia ou através de outras carências materiais igualmente importantes. A situação inversa, ocorrência de fome na ausência de uma situação de pobreza, ocorre apenas excepcionalmente e sempre por tempo determinado, como por ocasião de guerras, cercos e cataclismas.

Ao fazer o levantamento e começar apontar as possíveis causas da fome e da pobreza na Região do Contestado, não há como não citar Josué de Castro (2003 p.13) "o qual dividia a sociedade não em burguesia e proletariado, mas entre os que não comem e os que não dormem porque têm fome e os que comem, mas não dormem com medo dos que têm fome".

\footnotetext{
Não há como esconder que a fome, nas suas diferentes formas de fome quantitativa ou fome qualitativa, é sempre um produto direto do subdesenvolvimento e que o subdesenvolvimento não é um fatalismo provocado pela força das coisas, mas um acidente histórico provocado pela força daps circunstâncias. 0 subdesenvolvimento e produto da má utilização dos recursos naturais e humanos realizada de forma a não conduzir à expansão econômica e a impedir as mudanças sociais indispensáveis ao processo de integração dos grupos humanos subdesenvolvidos dentro de um sistema econômico integrado (CASTRO, 2003, p. 52).
}

Quando Josué de Castro (2003) fala de subdesenvolvimento não é a ausência ou insuficiência de desenvolvimento, mas o produto de um tipo universal de desenvolvimento, mal conduzido. 0 subdesenvolvimento é um produto ou um subproduto do desenvolvimento, uma derivação inevitável da exploração econômica colonial ou neocolonial. É a concentração abusiva de riqueza.

O IDH se propõe a caracterizar os aspectos fundamentais do desenvolvimento humano, enfatizando as oportunidades que os indivíduos devem ter para estarem inclusos socialmente; é composto por indicadores de esperança de vida, escolaridade e renda. Juntamente com o Índice de Pobreza Humana (IPH), que combina a expectativa de vida inferior a 40 anos, a taxa de analfabetismo em adultos, a deficiência de acesso à fonte adequada de água e a proporção de crianças abaixo do peso para sua idade - avalia longevidade, conhecimento e nível de vida 
- convertem-se em bons indicadores de aferição das péssimas condições de vida que caracterizam a pobreza, em um contexto pluridimensional.

No que concerne à qualidade de vida, a Região do Contestado possui as cidades com os piores Índices de Desenvolvimento de Santa Catarina, fruto da concentração histórica da terra. No tocante à riqueza industrial, o destaque maior ainda é a indústria madeireira, a motivadora do plantation de pínus e concentradora das terras, sem mencionar fatores com as diversas formas de degradações ambientais.

Diante do exposto, apresentam-se os municípios que compõem a Região do Contestado juntamente com o IDHM, GINI e o Índice de Pobreza Humana (Tabela 01); vale ressaltar que algumas cidades possuem IDHM altos e índice de pobreza em porcentagem elevada. Isso se explica pela alta renda per capita de algumas empresas instaladas nos municípios, sendo que as mesmas elevam a renda per capita, porém, excluem e marginalizam a população. Pode-se citar as principais cidades que são polos regionais que apresentam alto IDHM e alto índice de pobreza como: Canoinhas, Mafra, Porto União, Caçador e Videira.

Tabela 1: IDHM dos Municípios da Região do Contestado - IDHM do menor para o maior valor, GINI e Índice de Pobreza.

\begin{tabular}{|l|l|l|l|l|}
\hline CIDADES & POPULAÇÃO & IDHM & GINI & ÍNDICE DE POBREZA \\
\hline Calmon & 3.387 & 0,622 & 0,42 & $43,47 \%$ \\
\hline Timbó Grande & 7.167 & 0,659 & 0,47 & $41,56 \%$ \\
\hline Três barras & 18.129 & 0,706 & 0,47 & $39,86 \%$ \\
\hline Lebon Régis & 11.838 & 0,649 & 0,45 & $38,70 \%$ \\
\hline Fraiburgo & 34.553 & 0,731 & 0,48 & $36,98 \%$ \\
\hline Caçador & 70.762 & 0,735 & 0,48 & $36,25 \%$ \\
\hline Monte Castelo & 8.346 & 0,675 & 0,44 & $33,99 \%$ \\
\hline Matos Costa & 2.839 & 0,657 & 0,45 & $33,25 \%$ \\
\hline Canoinhas & 52.765 & 0,757 & 0.49 & $32,22 \%$ \\
\hline Papanduva & 17.928 & 0,704 & 0,47 & $31,66 \%$ \\
\hline Porto União & 33.493 & 0,786 & 0,53 & $31,29 \%$ \\
\hline Videira & 47.188 & 0,764 & 0,47 & $30,77 \%$ \\
\hline Mafra & 52.912 & 0,777 & 0,49 & $29,56 \%$ \\
\hline Spalto Veloso & 4.301 & 0.784 & 0,55 & $28,42 \%$ \\
\hline
\end{tabular}




\begin{tabular}{|l|l|l|l|l|}
\hline Major Vieira & 7.479 & 0,690 & 0,46 & $27,20 \%$ \\
\hline Irineópolis & 10.448 & 0,699 & 0,54 & $26,29 \%$ \\
\hline Itaiópolis & 20.301 & 0,708 & 0,49 & $26,07 \%$ \\
\hline Bela Vista do Toldo & 6.004 & 0,675 & 0,46 & $22,49 \%$ \\
\hline Arroio Trinta & 3.502 & 0,764 & 0,45 & $20,18 \%$ \\
\hline Macieira & 1.826 & 0,662 & 0,39 & $19,99 \%$ \\
\hline Rio das Antas & 6.143 & 0,697 & 0,44 & $19,94 \%$ \\
\hline Pinheiro Preto & 3.147 & 0.777 & 0,45 & $17,94 \%$ \\
\hline Iomerê & 2.739 & 0,795 & 0,33 & $11,04 \%$ \\
\hline
\end{tabular}

Fonte: IBGE - CENSOS 2003 e 2010.

Isso é evidente na Região do Contestado, principalmente no que tange às diferenças de condições de vida que são marcadas por riquezas e pobrezas verificadas dentro do mesmo território, como, por exemplo, em Videira e Caçador (AMARP), Porto União, Canoinhas e Mafra (AMPLANORTE), cidades ricas e com alto IDH-M, enquanto na contramão aparecem Calmon, Matos Costa e Timbó Grande (AMARP), e Bela Vista do Toldo, Major Vieira e Três Barras, (AMPLANORTE), com os piores índices, somente para citar algumas (FIGURA 01).

Figura 01: Casa do município de Três Barras no bairro São Cristóvão.

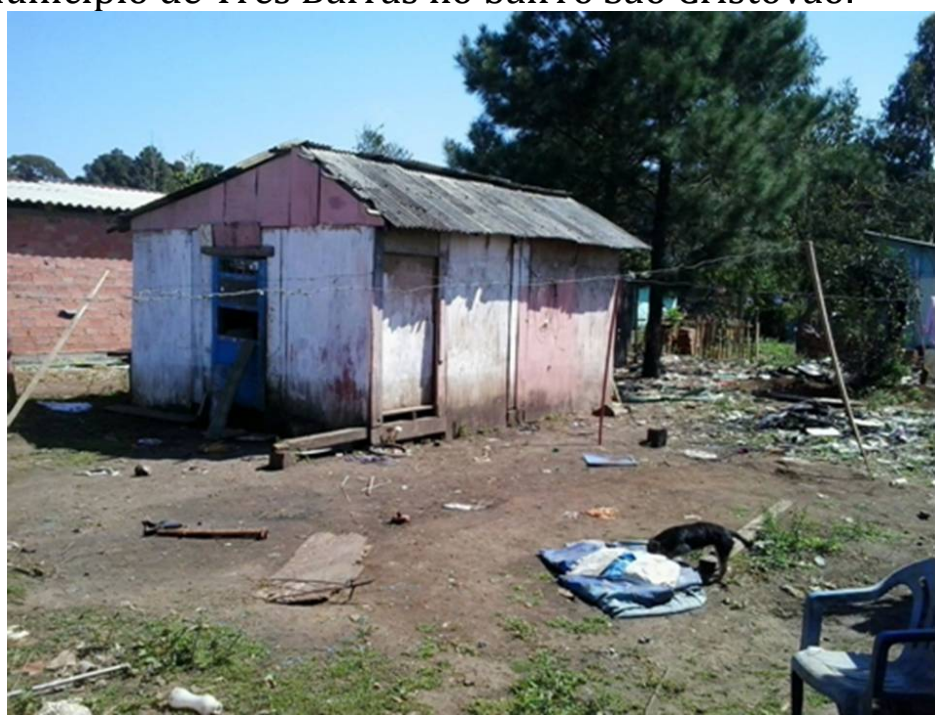

Fonte: Acervo da autora, 2014. 
Ao analisar a Figura 01, vários elementos podem ser observados no que tange à pobreza na Região do Contestado; as casas são feitas de placas de compensado, cobertas de Eternit e telhas em péssimas condições, material frágil para uma região onde as chuvas são constantes, não possuindo nenhuma segurança. A área em seu entorno não possui nenhuma horta que garante pelo menos algum tipo de alimentação; as famílias que residem nestas casas recebem bolsa família e sacolão da prefeitura municipal. Percebe-se a fragilidade no que tange à questão da saúde e habitação.

No gráfico a seguir, apresenta-se a porcentagem de pessoas que vivem em extrema pobreza, ou seja, é medida pela proporção de pessoas com renda domiciliar per capita inferior a R \$ 70,00. 0 Gráfico apresenta o senso de 1991, 2000 e 2010. A redução da extrema pobreza é evidente nestes 20 anos, porém vale ressaltar que esse decrescimento vem de políticas públicas federais como o bolsa família (Gráfico 1). 
Gráfico 1: Porcentagem de extremamente pobres.

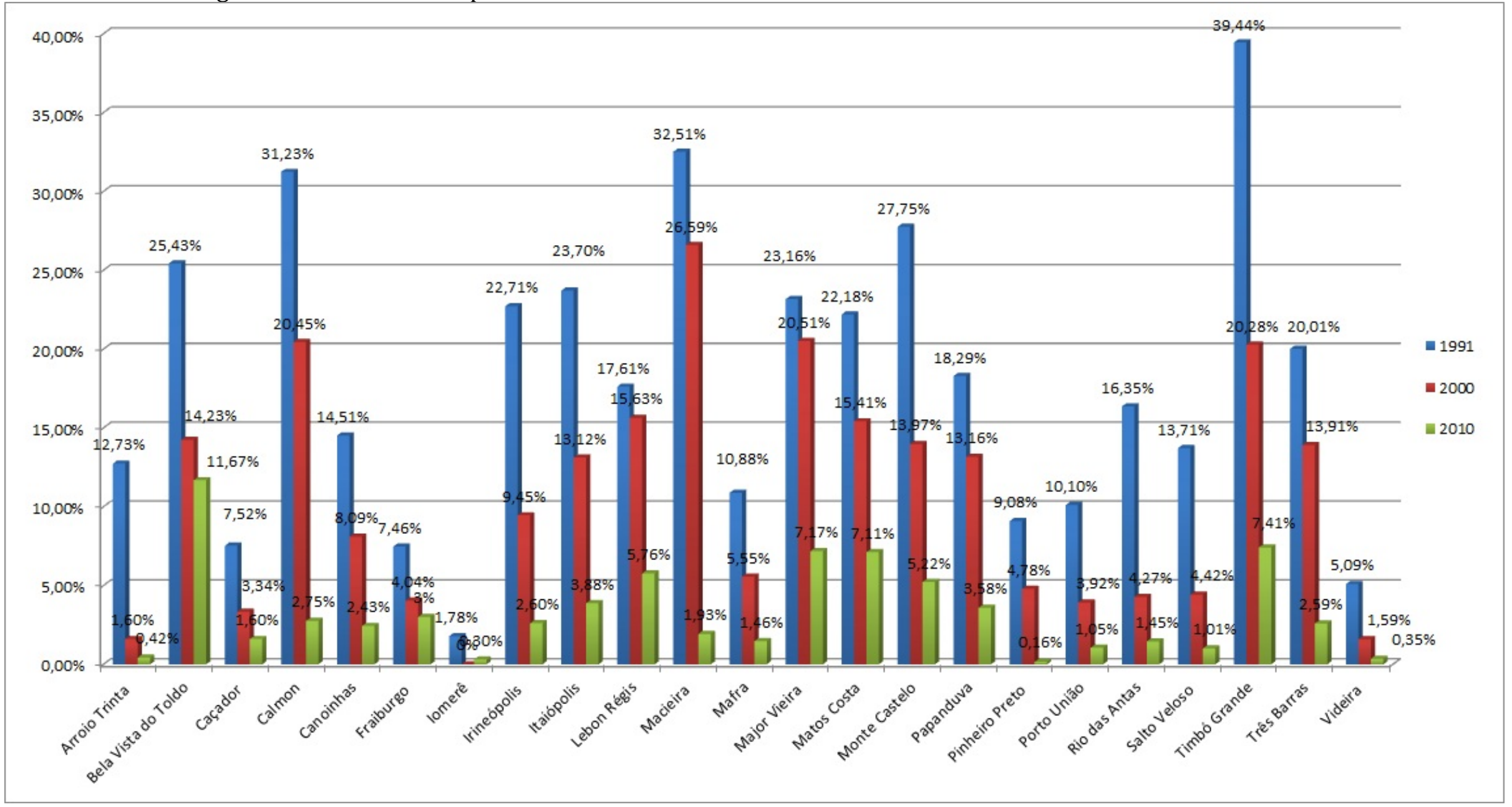

Fonte: IBGE 1991, 2000 e 2010. 
Além dos dados já apresentados, viu-se a necessidade de apresentar outros dados que comprovem a fome e a pobreza na Região do Contestado, baseado em Amartya Sen (2012). Embora o termo pobreza seja usado de modos diferentes, existem algumas associações claras, que restringem a natureza do conceito, e não estamos inteiramente livres para caracterizar a pobreza de qualquer modo que nos agrade. Pode se dar à pobreza tanto uma forma descritiva como uma relativa a políticas.

Na primeira visão, a identificação da pobreza é um reconhecimento de privação. Ela pode levar a uma recomendação de alguma política também, mas essa é uma característica derivada, e o exercício primordial consiste em decidir quem está verdadeiramente privado conforme isso é julgado na sociedade. A segunda visão simplesmente identifica a pobreza com a recomendação de alguma política, isto é, afirmação de que algo deve ser feito pela sociedade para combater essas deficiências. Na segunda visão, a pobreza é basicamente um assunto de identificação do foco da ação publica, e seu descritivo é derivativo apenas. Em contraste, a primeira visão faz da descrição o primário e, da conclusão sobre uma política, o secundário.

No que tange às políticas públicas estatais na Região do Contestado, analisou-se dados do Programa Bolsa Família, programa do Governo Federal que busca erradicar a pobreza no Brasil. O Programa Bolsa Família foi instituído pelo Governo Federal, pela Lei no 10.836, de 9 de janeiro de 2004, regulamentado pelo Decreto no 5.209, de 17 de setembro de 2004, alterado pelo Decreto n⿳0 6.157, de16 de julho de 2007. 0 programa é gerenciado pelo Ministério de Desenvolvimento Social e Combate à Fome (MDS) e beneficia famílias pobres (com renda mensal por pessoa de $\mathrm{R} \$ 70,01$ a $\mathrm{R} \$ 140,00$ ) e extremamente pobres (com renda mensal por pessoal de até $\mathrm{R} \$ 70,00$ ).

No Estado de Santa Catarina, o total de famílias inscritas no Cadastro Único, em novembro de 2015, era de 460.113, dentre as quais: 94.292 famílias com renda per capita familiar de até $\mathrm{R} \$ 77,00,73.772$ famílias com renda per capita familiar de até $\mathrm{R} \$$ $154,00,145.849$ famílias com renda per capita até meio salário mínimo e 146.200 famílias com renda per capita acima de meio salário mínimo. Segundo dados do MDS, o Programa do Bolsa Família (PBF) beneficiou, no mês de janeiro de 2016, 127.262 famílias, representando uma cobertura de $74,2 \%$ da estimativa de famílias pobres do município. As famílias receberam um valor médio de $\mathrm{R} \$ 147,31$. 
O estado de Santa Catarina, segundo o IBGE (2010), possui uma população de $6.248,436$ pessoas, realizando uma analise subjetiva, considerando que cada família seja composta por 4 pessoas, hoje seriam 377,168 (Trezentos e setenta e sete mil cento e sessenta e oito) pessoas na pobreza, ou seja, vivem com uma renda per capita de até $\mathrm{R} \$$ 77,00 .

Diante do exposto, apresenta-se um gráfico síntese com diagnóstico do Bolsa Família em cada município que integra a Região do Contestado. Os dados são do MDS Ministério do Desenvolvimento Social e Combate à Fome (2015/2016) certificados com os CRAS - Centro de Referência da Assistência Social e Secretarias de Serviço Social de cada município da Região do Contestado, vale destacar que o gráfico 02 apresenta dados dos anos 2004 a 2016. 
Gráfico 2: Número de famílias atendidas pelo Programa Bolsa Família na Região do Contestado.

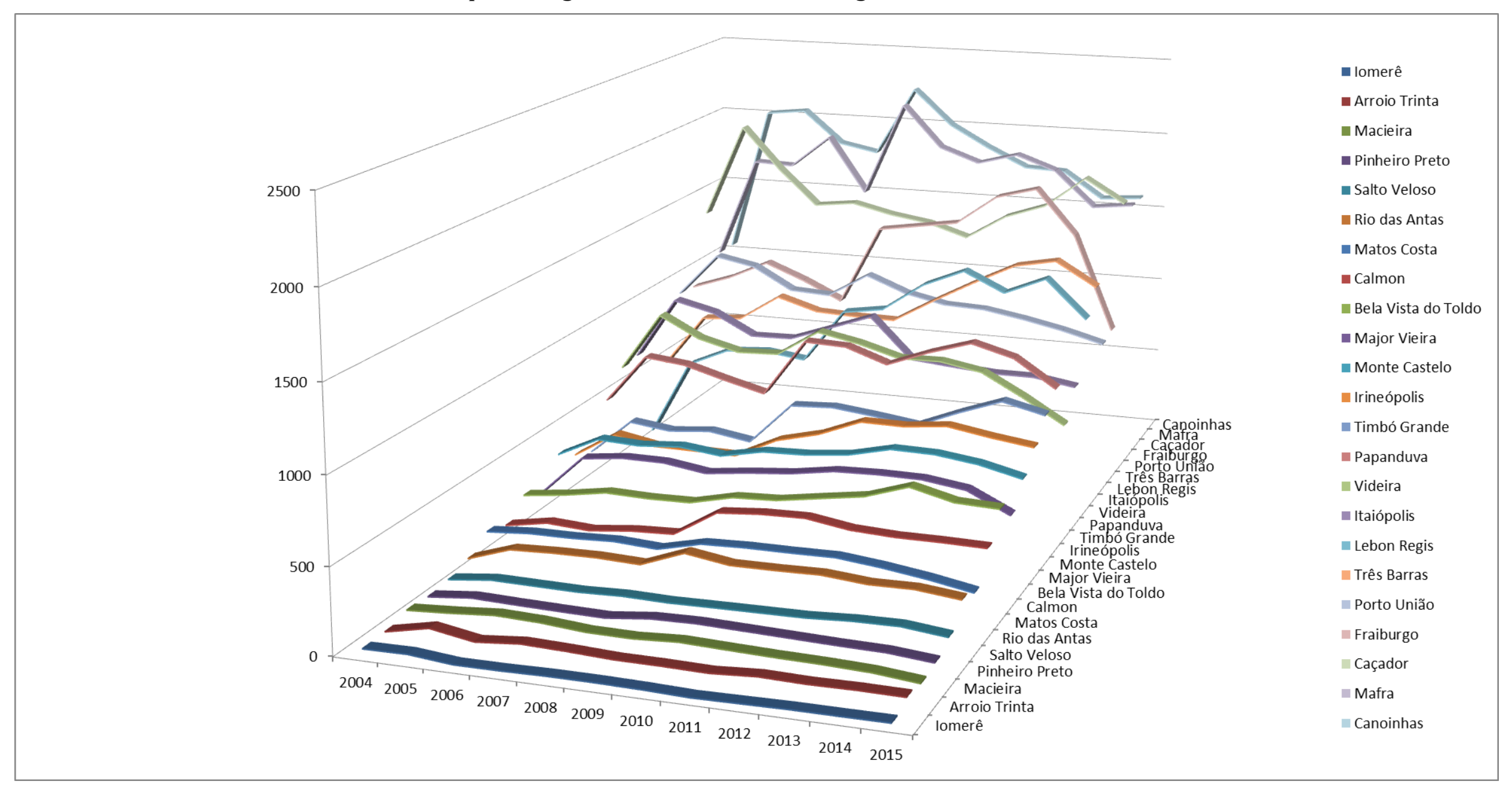

Fonte: A autora, Adaptado de Ministério do Desenvolvimento Social e Combate à Fome (2014). 
Ao analisar o gráfico da distribuição do Bolsa Família, nos municípios que compõem a Região do Contestado, não há duvidas que o retrato regional da pobreza é alto. Tomando como base o ano de 2015, a região apresenta 427.127 mil habitantes que compõem a Região do Contestado e 14.710 famílias são atendidas pelo programa, o que totaliza 58.840 mil habitantes (fazendo um cálculo de 4 pessoas por família). Vale ressaltar que neste número estão algumas famílias pobres (com renda mensal por pessoa de $\mathrm{R} \$ 70,01$ a $\mathrm{R} \$ 140,00$ ) e, na sua maioria, as extremamente pobres (com renda mensal por pessoal de até $R \$ 70,00$ ). No Gráfico 3, apresenta-se uma síntese do número de bolsas famílias distribuídas na Região do Contestado de 2004 a 2015.

Gráfico 3: Número de famílias atendidas pelo Programa Bolsa Família na Região do Contestado.

\section{Número de Famílias Atendidas pelo Programa Bolsa \\ Família na Região do Contestado(SC)}

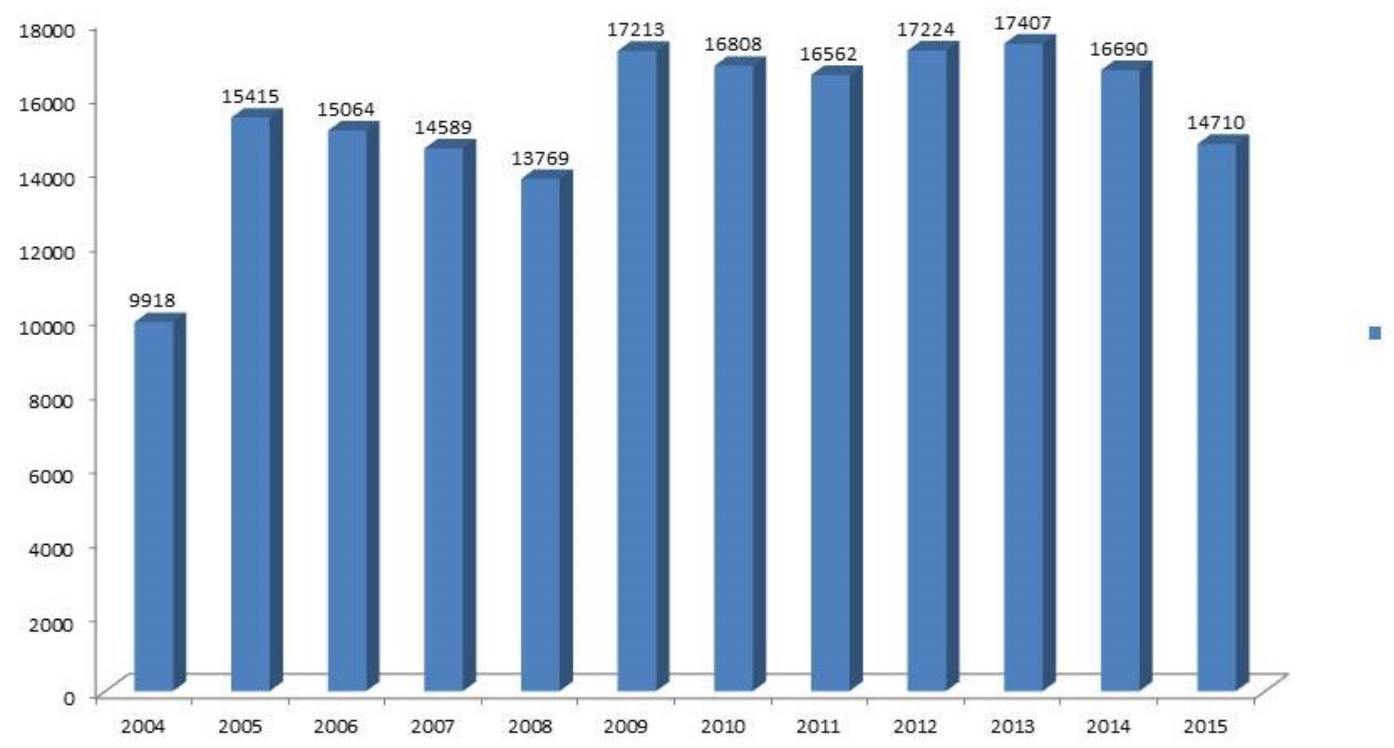

Fonte: A autora, Adaptado de Ministério do Desenvolvimento Social e Combate à Fome (2014).

Ao refletir a pobreza e a fome na Região do Contestado, percebe-se que é uma pobreza produzida politicamente pelas empresas e instituições globais atuantes naquela região. Estas, de um lado, pagam para criar soluções localizadas, parcializadas, segmentadas, com programas de atenção aos pobres, querendo passar a impressão de se interessar pelos 
desvalidos, quando estruturalmente é o grande produtor de pobreza. E isso se dá com a colaboração passiva ou ativa dos governos locais.

Para caracterizar a pobreza, é necessário estabelecer um padrão mínimo de necessidades básicas. Para definir esse limite, há três abordagens comumente utilizadas: medida absoluta, medida relativa e medida subjetiva.

O enfoque biológico define a linha de pobreza a partir dos requisitos nutricionais mínimos da dieta alimentar, definindo o valor aproximado para a renda a ser gasta para o atendimento desses requisitos. Por básicas entendem-se necessidades como alimentação, moradia, vestuário e serviços essenciais: água potável, saneamento, transporte público, serviços médicos e escolas.

A região do Contestado é pobre, com muitas terras improdutivas e campos isolados sendo engolidos por reflorestamento de pinus e álamo (Figura 15 e 16), com isso desaparecem as araucárias, e persiste o monocultivo do tabaco (principalmente no município referência de pobreza rural - Bela Vista do Toldo) (Figura 17), indústrias frigoríficas e multinacionais dominando, como se o avançar do capital estrangeiro nunca tivesse cessado.

\begin{abstract}
A fome reinante nas terras sul-americanas é uma consequência direta do seu passado histórico: da história da exploração colonial, de tipo mercantil, desdobrada em ciclos sucessivos da economia destrutiva, ou pelo menos desequilibrante, da integridade econômica do continente - o ciclo do ouro, o ciclo do açúcar, o ciclo do petróleo, etc. Durante cada um desses ciclos, vemos tôda uma região absorvendo-se inteiramente no monocultivo ou na monoexploração de um produto, esquecendo tudo o mais e degradando destarte as riquezas naturais e as possibilidades de abastecimento da região. [...]. Monocultura e latifúndio constituem dois dos maiores males, que entravam de maneira terrível seu desenvolvimento agrícola e, consequentemente, suas possibilidades de abastecimento alimentar (CASTRO, 1961, p. 190).
\end{abstract}

Foi possível perceber que a desigualdade social, a fome e a pobreza fizeram parte de todo o processo histórico, estando presentes muitas vezes, nas principais pautas de discussão, porém, não como objetos de efetivas ações que buscassem o enfrentamento da problemática. Esta pesquisa busca ajudar no rompimento da invisibilidade da pobreza e do silêncio impostos pela Guerra do Contestado, uma das maiores ocorridas em solo latino-americano, cuja região é ocupada pelos descendentes dos poucos sobreviventes ao genocídio ocorrido entre 1912 e 1916-17. 


\section{CONSIDERAÇÕES FINAIS}

Buscou-se, nesta pesquisa, compreender se a fome e a pobreza existentes na Região do Contestado seriam uma herança da Guerra do Contestado ou uma questão social, politica, econômica e cultural. A heterogeneidade das informações levantadas para este trabalho constituiu-se em uma dificuldade para a elaboração desta pesquisa com meticulosidade, isso devido à divergência entre os dados pesquisados. As informações fornecidas pelo IBGE não correspondiam com os dados divulgados pelo MDS, que não condizem com os dados fornecidos pelo IPEA, mas, mesmo em meio à divergência dos números, as informações sobre a fome estavam presentes em todos os bancos de dados levantados.

Por anos, a fome foi considerada um tabu, pois como bem colocou Josué de Castro (1961 p. 49) "quanto ao tabu da fome, havia razões ainda mais fortes do que os preconceitos de ordem moral. Razões cujas raízes mergulhavam no escuso mundo dos interesses econômicos, dos interesses de minorias dominantes e privilegiadas, que sempre trabalharam para escamotear o exame do fenômeno da fome do panorama intelectual moderno". Desta forma, analisando a Região do Contestado, concluiu-se que a fome e a desnutrição cresceram com as políticas neoliberais, não por falta de alimentos, mas pela ausência de direitos e renda.

No decorrer das análises da pesquisa em tela, a fome e a pobreza na Região do Contestado são históricas, na obra de Vinhas de Queiroz, existem relados dos sobreviventes da Guerra do Contestado, crianças à época, que hoje são anciões de mais de 100 anos e que trazem a memória da dor da Guerra e da fome por ela geradas, coisa que não viviam antes do deflagrar da guerra em si. Nesses relatos durante e após a guerra a fome torna-se fato presente nas vidas dessas pessoas. Outros autores relatam a existência da fome antes do período da Guerra, entretanto, a Guerra do Contestado teve como consequência uma grave desestruturação da organização socioeconômica da região, causando o estabelecimento da fome conjuntural em uma escala sem precedentes.

Que a Região do Contestado apresenta graves problemas sociais isso não é novidade, como bem destaca Waquil (2013) que as regiões localizadas no Planalto Norte e no Oeste Catarinense (que compõem a região do contestado), especialmente as mais próximas à divisa com o Paraná, são as que apresentam os percentuais mais elevados de pessoas pobres. 
Também são as regiões com menores valores do IDHM, bem como com menores acessos a serviços públicos (abastecimento de água, esgoto, energia elétrica e telefonia). Além do que foi destacado por Waquil, podem ser citados os índices apresentados pelo MDS e IBGE, no que tange à questão da pobreza. Porém, como exibido nesta pesquisa, a própria secretaria estadual não sabe que esta situação existe, ou não deseja que isso venha à tona, talvez a fome e a pobreza sejam para eles ainda um tabu, e para camuflar os dados apresentados incluam Joinville e Jaraguá do Sul (cidades com PIB elevado) como cidades de uma região Norte que não existe na regionalização oficial catarinense.

Não se acredita que esse abandono, pois a região é tida como abandonada pelos poderes públicos estaduais, seja pelo distanciamento da capital, pois se assim fosse as cidades mais desenvolvidas do Meio-Oeste Catarinense (como Videira e Caçador) ou mesmo do Oeste (Xanxerê e Chapecó) deveriam apresentar-se como municípios subdesenvolvidos, o que não é o caso. A realidade verificada com os estudos aqui apresentados demonstram que faltam políticas públicas voltadas à essa região - no caso a do Contestado -, além de uma força de representação política mais atuante, falta de vontade política municipal, regional e estadual, pois as poucas políticas públicas, que efetivamente apresentaram resultados nos últimos anos na região, são frutos de ações de programas do governo federal.

Só será possível compreender a fome e a pobreza na Região do Contestado se for considerado que o que houve naquela região, desde a guerra do Contestado, é decorrente de uma crise estrutural. Acumularam-se, por meio de anos, problemas sociais de toda a espécie, nunca resolvidos, agravando-se os conflitos latentes entre várias classes e camadas, e a estrutura social apresentada pelo coronelismo, não se pode afirmar que hoje já esteja terminada. 0 modelo escolhido, para não dizer imposto para estas sociedades, onde lhes foi negada a distribuição de bens e riquezas, foi concebido para atender apenas a alguns senhores do capital da Guerra.

Conclui-se que, diante dos dados aqui apresentados, a Região do Contestado é atingida tanto pela pobreza como pela fome. Recorrendo aos relatos e fatos históricos, é possível confirmar que a fome e a pobreza na Região do Contestado tiveram sua gênese de forma conjuntural, fruto da Guerra do Contestado, relembrando de que a mesma ocorreu pela entrada do Capital estrangeiro na região, ou seja, tanto pela construção da Ferrovia São PauloRio Grande, como pela Lumber Company, que ganhou o direito de explorar quinze quilômetros 
de cada lado das margens da ferrovia, vindo a expulsar as famílias caboclas que nessas terras viviam, deixando-as sem-terra e desiquilibradas econômica e socialmente.

A fome permanece! A pobreza permanece! O Contestado permanece em Guerra! A Guerra segue com fome além da comida, pois há todo um patrimônio material e imaterial se perdendo pela ação das intempéries. A Guerra segue pela falta de políticas públicas em todos os níveis para a região, sobretudo as que poderiam aumentar a dignidade e a qualidade de vida da população. A Guerra segue com numerosas possibilidades de pesquisas futuras, para a Geografia e outras áreas do conhecimento, pois o Contestado carece de estudos que rompam sua invisibilidade e o silêncio imposto pelos vencedores, pelos donos do poder ou dos poderes que minam a vida regional.

\section{REFERÊNCIAS}

BRASIL. Discurso de posse do Presidente Lula em 1o de janeiro de 2003. Disponível em: <http://www.info.planalto.gov.br/>. Acesso em: 10 de outubro de 2010.

CASTRO, J. Fome: um tema proibido - últimos escritos de Josué de Castro. Organizado por Anna Maria de Castro (org). Rio de Janeiro: Civilização Brasileira, 2003.

CASTRO, J. Geografia da Fome: o dilema brasileiro: pão e aço. Rio de Janeiro: Civilização brasileira, Ed. 14, 2001.

CASTRO, J. Geopolítica da Fome: Ensaios sobre os problemas de alimentação e de população do mundo. 6ª ed. v.1. São Paulo: Editora Brasiliense, 1961.

CASTRO, J. 0 Livro Negro da Fome. 2 2aㅡ ed. São Paulo: Editora Brasiliense, 1966.

FAO. Número de vítimas da fome cai para menos de 800 milhões: a erradicação é o próximo objetivo. Disponível em: http://www.fao.org/news/story/pt/item/288582/icode/2015. Acesso em: 15 de outubro de 2015.

FRAGA, N. C. Contestado, o território silenciado. Florianópolis: Insular, 2009.

FRAGA, N. C. Mudanças e permanências na rede viária do contestado: uma abordagem acerca da formação territorial no Sul do Brasil. Tese (Doutorado em Meio Ambiente e Desenvolvimento) - Universidade Federal do Paraná, Curitiba - PR, p.188, 2006.

FRAGA, N. C. Vale da Morte: O Contestado visto e sentido. Entre a cruz de Santa Catarina e a espada do Paraná. Blumenau: Ed. Hemisfério Sul, 2010.

GALEANO, E. As Veias Abertas da América Latina. Rio de Janeiro: Paz e Terra, 22 ed., 1986.

IBGE - INSTITUTO BRASILEIRO DE GEOGRAFIA E ESTATÍSTICA. Censo demográfico Porcentagem de extremamente pobresde 1991, 2000 e 2010. Disponível em: 
http://www.censo2010.ibge.gov.br/noticiascenso?view=noticia\&id=3\&idnoticia=2019\&busca=1\&t=indicadoressociais-municipais-2010incidencia-pobreza-maior-municipios-porte-medio. Acesso em: 12 de maio de 2014.

IBGE - INSTITUTO BRASILEIRO DE GEOGRAFIA E ESTATÍSTICA. Censo demográfico de 2003 e 2010. Disponível em: http://memoria.ibge.gov.br/sinteses-historicas/historicos-doscensos/censos-demograficos. Acesso em: 12 de maio de 2014.

IBGE, Dados da extrema pobreza. 2003. Disponível em http://www.cidades.ibge.gov.br/xtras/home.php. Acesso em: 10 de setembro de 2014.

MACHADO, P. P. Lideranças do Contestado: a formação e a atuação das chefias caboclas (1912-1916). Campinas, SP: Editora da UNICAMP, 2004.

MAZOYER, M; ROUDART, L. História das agriculturas no mundo: do neolítico à crise contemporânea. São Paulo: Editora Unesp; Brasília, DF: NEAD, 2010.

MDS. Boletim ministério do desenvolvimento social de combate a fome. Disponível em: http://aplicacoes.mds.gov.br/sagi/RIv3/geral/index.php. Acesso em: 21 de dezembro de 2015.

MINISTÉRIO DO DESENVOLVIMENTO SOCIAL E COMBATE À FOME (MDS). Boletim ministério do desenvolvimento social de combate a fome. Disponível em: http://aplicacoes.mds.gov.br/sagi/RIv3/geral/index.php. Acesso em: 21 de novembro de 2014.

MONTEIRO, D. T. Os errantes do novo século: Um estudo sobre o surto milenarista do Contestado - São Paulo: Duas Cidades, 1974.

THOMÉ, N. Sangue, Suor e Lágrimas no Chão Contestado. Caçador (SC): UnC, 1992.

ZIEGLER, J. A fome no mundo explicada a meu filho. Petrópolis: Editora Vozes, 2002.

ZIEGLER, J. Destruição em massa geopolítica da fome. São Paulo: Cortez, 2013. 